\title{
Hydrogen sulfide attenuates the inflammatory response in a mouse burn injury model
}

\author{
JIANHONG ZENG ${ }^{*}$, XIANHE LIN ${ }^{2 *}$, HAIPENG FAN $^{3}$ and CHANGQING LI ${ }^{4}$ \\ ${ }^{1}$ College of Pharmacy, Guilin Medical University, Guilin, Guangxi 541004; ${ }^{2}$ Department of Cardiology, \\ The First Affiliated Hospital of Anhui Medical University, Hefei, Anhui 230022; ${ }^{3}$ Department of Anesthesiology, \\ Affiliated Hospital of Shandong University of Traditional Chinese Medicine, Jinan, Shandong 250011; ${ }^{4}$ Department of Pharmacy, \\ The Second Affiliated Hospital of Chongqing Medical University, Yuzhong, Chongqing 400041, P.R. China
}

Received March 11, 2013; Accepted July 5, 2013

DOI: $10.3892 / \mathrm{mmr} .2013 .1610$

\begin{abstract}
Hydrogen sulfide $\left(\mathrm{H}_{2} \mathrm{~S}\right)$ is a naturally occurring gaseous transmitter, which is important in normal physiology and disease. In the present study, the involvement of $\mathrm{H}_{2} \mathrm{~S}$ in the regulation of the immune response induced by burn injury was investigated in mice. Adult male C57BL/6 mice were subjected to burn injuries and treated with vehicle $(0.9 \%$ sodium chloride, $\mathrm{NaCl} ; 100 \mathrm{ml} / \mathrm{kg}$ body weight; subcutaneously, s.c.) or the $\mathrm{H}_{2} \mathrm{~S}$ donor (sodium hydrosulfide, NaHS; $2 \mathrm{mg} / \mathrm{kg}$ body weight; s.c.). Compared with the controls, mice which received burn injuries exhibited a significant decrease in plasma $\mathrm{H}_{2} \mathrm{~S}$ levels. Moreover, the levels of tumor necrosis factor (TNF)- $\alpha$, interleukin (IL)-6 and IL-8 significantly increased, while IL-10 levels were decreased, compared with that of the controls in the plasma of mice subjected to burn injuries. Myeloperoxidase (MPO) activity in the liver tissue of injured mice was also markedly higher compared with that of the control group. However, the administration of NaHS significantly decreased the levels of TNF- $\alpha$, IL- 6 and IL- 8 but increased the levels of IL-10 in the plasma of mice subjected to burn injuries. In addition, the MPO activity was decreased by $\mathrm{NaHS}$. These results suggested that $\mathrm{H}_{2} \mathrm{~S}$ regulates the inflammatory response induced by burn injury by modulating the levels of TNF- $\alpha$, IL-6, IL-8 and IL-10. Thus, it was proposed that the administration of the $\mathrm{H}_{2} \mathrm{~S}$ donor, NaHS, may be a
\end{abstract}

Correspondence to: Professor Changqing Li, Department of Pharmacy, The Second Affiliated Hospital of Chongqing Medical University, 76 Linjian Road, Yuzhong, Chongqing 400041, P.R. China

E-mail: isfjgt@126.com

*Contributed equally

Abbreviations: $\mathrm{H}_{2} \mathrm{~S}$, hydrogen sulfide; SIRS, systemic inflammatory response syndrome; TNF- $\alpha$, tumor necrosis factor- $\alpha$; MPO, myeloperoxidase; NaHS, sodium hydrogen sulfide; TBSA, total body surface area

Key words: burn injury, hydrogen sulfide, inflammation, cytokine useful therapy against the exaggerated immune response that is associated with burn injury.

\section{Introduction}

Burn injuries, which are characterized by heat-induced tissue coagulation at the time of injury, constitute a global public health problem (1). The systemic effects of burn injuries include the release of inflammatory cytokines produced by inflammatory cells and the vascular endothelium. These cytokines regulate lymphocyte function through the activation of tumor necrosis factor (TNF)- $\alpha$, interleukin (IL)-1b, IL-2, IL-4, IL-6, IL-8, IFN-a and IFN-b, or the inhibition of IL-10 and TGF- $\beta$ immune responses (2). Inflammation is important in pathogenesis, however, the imbalance between inflammatory and anti-inflammatory cytokines induced by burn injury aggravates the inflammatory response. This may result in the development of sepsis or systemic inflammatory response syndrome due to immune dysfunction, which increases the risk of mortality $(3,4)$. Thus far, advances remain limited in the manipulation of the inflammatory response to treat burn injuries.

Previously, the third signaling gasotransmitter, hydrogen sulfide $\left(\mathrm{H}_{2} \mathrm{~S}\right)$, was demonstrated to exhibit physiological and physiopathological roles in vivo and in vitro $(5,6)$. An increasing number of studies suggest that $\mathrm{H}_{2} \mathrm{~S}$ exerts protective effects against various stimuli-triggered injuries in numerous organs, including the heart, liver and kidneys $(7,8)$. However, the importance of $\mathrm{H}_{2} \mathrm{~S}$ in inflammation is only recently beginning to be elucidated, and the exact role of $\mathrm{H}_{2} \mathrm{~S}$ in inflammation remains controversial, as pro-inflammatory and anti-inflammatory effects have been demonstrated (9). Certain studies have determined the pro-inflammatory effects of $\mathrm{H}_{2} \mathrm{~S}$. These studies showed that inflammation was correlated with increased levels of plasma $\mathrm{H}_{2} \mathrm{~S}$ and tissue $\mathrm{H}_{2} \mathrm{~S}$ synthesizing enzyme activity. In addition, the inhibition of $\mathrm{H}_{2} \mathrm{~S}$ synthesis by DL-propargylglycine (PAG) treatments led to reduced inflammation (10-12). However, other studies have observed anti-inflammatory effects of $\mathrm{H}_{2} \mathrm{~S}$. Treatments with either $\mathrm{H}_{2} \mathrm{~S}$ releasing non-steroidal anti-inflammatory drugs or $\mathrm{H}_{2} \mathrm{~S}$ donors (sodium hydrosulfide, NaHS) showed anti-inflammatory activity in various models of inflamma- 
tion (13-15). In addition, in lipopolysaccharide-stimulated microglias and astrocytes, $\mathrm{H}_{2} \mathrm{~S}$ exerted an anti-inflammatory effect (16).

In the present study, it was hypothesized that $\mathrm{H}_{2} \mathrm{~S}$ is important in the regulation of the inflammatory response induced by burn injury. Thus, the therapeutic potential of NaHS, an $\mathrm{H}_{2} \mathrm{~S}$ donor in an in vivo model of burn-related inflammation in mice, was investigated. It was determined that $\mathrm{H}_{2} \mathrm{~S}$ was anti-inflammatory and suppressed the inflammatory response associated with burn injury.

\section{Materials and methods}

Animals. Adult male C57BL/6 mice (age, 6-8 weeks; weight, 21-24 g) were obtained from the Second Military Medical University (Shanghai, China). Mice were individually housed in laminar flow cabinets under specific pathogen-free conditions with access to food and water ad libitum. The animals were acclimatized for 1 week prior to the experiment, and maintained throughout at standard conditions of $50 \%$ relative humidity, $24 \pm 1^{\circ} \mathrm{C}$ and a 12 -h light-dark cycle. The mice were randomized into two groups; the first was a sham group that did not receive burn injuries $(n=7)$ and the second group received burn injuries. Mice in the second group were then randomly subdivided into three groups ( $n=7$ per group): An untreated group, a saline group that received the vehicle $(0.9 \%$ sodium chloride, $\mathrm{NaCl} ; 100 \mathrm{ml} / \mathrm{kg}$ body weight; subcutaneously, s.c.) and an NaHS group that was treated with NaHS ( $2 \mathrm{mg} / \mathrm{kg}$ body weight; s.c.). All animal experiments were conducted according to the National Institutes of Health's Guide for the Care and Use of Laboratory Animals (2011, ISBN-13: 978-0-309-15400-0), and were approved by the Institutional Animal Care and Use Committee of the Second Military Medical University.

$\mathrm{H}_{2} \mathrm{~S}$. The dehydrated NaHS powder (anhydrous; Beijing Chemical Reagents Company, Beijing, China) was dissolved in isotonic saline $(0.9 \%)$ immediately prior to administration. For the treatment groups, either normal saline or NaHS were subcutaneously injected into the mice using a 32-gauge needle.

Mouse injury model. The burn injury model was generated as described previously (17). Briefly, mice were anesthetized by intraperitoneal injection of pentobarbital sodium $(75 \mathrm{mg} / \mathrm{kg})$, then the dorsum was cleansed and shaved with electrical hair clippers. Subsequently, $40 \%$ of the total body surface area (TBSA) was exposed to a $95^{\circ} \mathrm{C}$ water bath for $10 \mathrm{sec}$, followed by $4^{\circ} \mathrm{C}$ water for $45 \mathrm{sec}$ to halt the burning process. A full-thickness skin burn was confirmed by its characteristics with the loss of epidermis and dermis. Mice were revived from unconsciousness by intraperitoneal application of $1 \mathrm{ml}$ sterile saline $1 \mathrm{~h}$ after burning. The group of mice without exposure to boiling water served as controls. Mice were then immediately injected with the vehicle or sodium sulfide $(2 \mathrm{mg} / \mathrm{kg}$ body weight, s.c.). After $10 \mathrm{~h}$, mice were sacrificed by $\mathrm{CO}_{2}$ asphyxiation. Blood samples were taken via direct cardiac puncture for analysis by enzyme-linked immunosorbent assay (ELISA) assay. Liver samples from each group were collected and frozen immediately in liquid nitrogen for subsequent measurement of tissue myeloperoxidase (MPO) activity.
Detection of plasma $\mathrm{H}_{2} \mathrm{~S}$ content. Blood samples for each group were taken in heparinized tubes via direct cardiac puncture and centrifuged at 726 x g for 5 min. Plasma $\mathrm{H}_{2} \mathrm{~S}$ concentration was measured with an ELIT Ion Analyzer (ELIT 9801; Electro Analytical Instruments Ltd., London, $\mathrm{UK}$ ) as described previously (18). In brief, $0.5 \mathrm{ml}$ sulfide antioxidant buffer (SAOB; NaOH $2.35 \mathrm{~mol} / \mathrm{l}$ and EDTA $0.27 \mathrm{~mol} / \mathrm{l}$ ) was added to $0.5 \mathrm{ml} \mathrm{H}_{2} \mathrm{~S}$ standard solutions $(10,20$, $30,40,50,60$ and $80 \mu \mathrm{mol} / 1$, respectively). A sulfide-sensitive electrode (ELIT 8225) and a reference electrode (ELIT 003n; Electro Analytic Instruments Ltd.) were rinsed in deionized water, blotted dry and immersed in a mixture of SAOB and $10 \mu \mathrm{mol} / 1 \mathrm{H}_{2} \mathrm{~S}$ standard solution. When a stable reading was displayed, the voltage value $(\mathrm{mV})$ was recorded. This procedure was repeated for the other combinations of SAOB and different concentrations of $\mathrm{H}_{2} \mathrm{~S}$ standard solutions. When all the standards were measured, the standard curve of voltage versus concentration was plotted. The electrodes were washed as previously, and the samples were measured in the same way as the measurement for the standard solution. The sample data were plotted on the standard curve and the sample concentration was obtained.

Measurement of MPO activity. Neutrophil sequestration in the liver was quantified by measuring the tissue MPO activity as previously described (19). Liver samples were thawed, homogenized in $20 \mathrm{mM}$ phosphate buffer ( $\mathrm{pH} 7.4$ ), centrifuged $\left(10,000 \mathrm{x} \mathrm{g}\right.$ for $10 \mathrm{~min}$ at $\left.4^{\circ} \mathrm{C}\right)$ and the resulting pellet was resuspended in $50 \mathrm{mM}$ phosphate buffer $(\mathrm{pH} 6.0)$ containing $0.5 \%$ (w/v) hexadecyltrimethylammonium bromide (Sigma-Aldrich, St. Louis, MO, USA). The suspension was subjected to four cycles of freezing and thawing, and further disrupted by sonication (40 sec). The sample was then centrifuged $\left(10,000 \mathrm{x}\right.$ g for $5 \mathrm{~min}$ at $\left.4^{\circ} \mathrm{C}\right)$ and the supernatant was used for the MPO assay. The reaction mixture consisted of the supernatant $(50 \mu \mathrm{l}), 1.6 \mathrm{mM}$ tetramethylbenzidine (Sigma-Aldrich), $80 \mathrm{mM}$ sodium phosphate buffer ( $\mathrm{pH} 5.4$ ) and $0.3 \mathrm{mM}$ hydrogen peroxide $(50 \mu \mathrm{l})$. This mixture was incubated at $37^{\circ} \mathrm{C}$ for $110 \mathrm{sec}$, the reaction was terminated with $50 \mu \mathrm{l}$ of $0.18 \mathrm{M} \mathrm{H}_{2} \mathrm{SO}_{4}$ and the absorbance was measured at $450 \mathrm{~nm}$. The absorbance was then corrected for the DNA content of the tissue sample and results were expressed as the enzyme activity.

Measurement of plasma inflammatory and anti-inflammatory cytokine levels by ELISA. Blood samples from each group were collected in heparinized tubes via direct cardiac puncture and centrifuged at $726 \mathrm{x}$ g. Cytokine levels were quantified by a sandwich ELISA using ELISA kits (Quantikine ${ }^{\circledR}$ Colorimetric Sandwich ELISAs; R\&D Systems, Minneapolis, MN, USA) according to the manufacturer's instructions. Briefly, samples $(100 \mu \mathrm{l})$ and IL-6 standards (0, 62.5, 125, 250, 500 and $1000 \mathrm{pg} / \mathrm{ml}$ ) were added to the wells. Each was tested in duplicate. Following $1 \mathrm{~h}$ of incubation at $37^{\circ} \mathrm{C}$, samples were removed and the plates were washed with a washing buffer (consisting of PBS, $10 \mathrm{mmol} / \mathrm{l}, \mathrm{pH} 7.4$ and Tween 20, 0.1\%). Anti-rat IL-6 biotin (100 $\mu \mathrm{l})$ was added to each well of the plates and left for $30 \mathrm{mins}$ at $37^{\circ} \mathrm{C}$. Following five additional washing steps, $100 \mu \mathrm{l}$ horseradish peroxidase was added to the wells and left for $30 \mathrm{mins}$ at $37^{\circ} \mathrm{C}$. Subsequent to a further wash, 
$100 \mu 1$ tetramethylbenzidine substrate was added to each well for color development. The mixture was incubated in the dark for 30 mins at room temperature. Following the termination of the reaction by the addition of $100 \mu \mathrm{l}$ stop solution to each well, the optical density (OD) values at $450 \mathrm{~nm}$ were measured by a Bio-Rad ELISA reader (iMark Microplate Absorbance Reader; Bio-Rad, Richmond, CA, USA). The standard curve of the OD value versus the concentration of IL- 6 was obtained. The sample data were plotted on the standard curve and the sample IL-6 concentration was determined. The same method was utilized for the analysis of the plasma levels of TNF- $\alpha$, IL-8 and IL-10.

Statistical analysis. SPSS Version 17.0 software (SPSS for Windows, Inc., Chicago, IL, USA) was used for all statistical analyses. All results are presented as the mean \pm SEM. Statistical analysis of the data was performed using standard one-way analysis of variance followed by a least significant difference post hoc test. Bonferroni's correction was used to adjust for multiple comparisons. A two-tailed Student's paired t-test was also used to compare the difference in values between two groups. $\mathrm{P}<0.05$ was considered to indicate a statistically significant difference.

\section{Results}

Burn injury decreases the $H_{2} S$ levels in the plasma. As shown in Fig. $1, \mathrm{H}_{2} \mathrm{~S}$ levels in the plasma of mice were significantly lower in the groups subjected to burn injury compared with those of the sham group $(\mathrm{P}<0.05)$. In addition, NaHS significantly increased the plasma $\mathrm{H}_{2} \mathrm{~S}$ levels compared with those of the burn control group that received no treatment $(\mathrm{P}<0.05)$.

Burn injury promotes the inflammatory response in rats, which is suppressed by the $\mathrm{H}_{2} \mathrm{~S}$ donor, NaHS. An ELISA assay demonstrated that the levels of IL-6, IL- 8 and TNF- $\alpha$ in the plasma of mice subjected to burn injuries were significantly higher than those of the sham group that received no injury ( $\mathrm{P}<0.01$, Fig. 2). Notably, the plasma levels of IL-10 in the injured group were significantly decreased compared with those in the sham group $(\mathrm{P}<0.01$, Fig. 2). Administration of NaHS in the mice that had received burn injuries significantly decreased the IL- 6 levels in the plasma compared with those that received saline or no treatment $(\mathrm{P}<0.05$, Fig. 2). Similarly, administration of NaHS significantly decreased the IL-8 and TNF- $\alpha$ levels in the plasma of injured mice compared with those that received saline or no treatment $(\mathrm{P}<0.05$, Fig. 2). However, the $\mathrm{H}_{2} \mathrm{~S}$ donor treatment significantly enhanced the IL-10 levels in the plasma of injured mice compared with those that received saline or no treatment $(\mathrm{P}<0.05$, Fig. 2). No significant differences were identified between the saline and the untreated groups.

NaHS decreases the enhanced MPO activity induced by burn injury. Tissue MPO activity, an indication of neutrophil inflammatory activity, was markedly increased in the livers of mice subjected to burn injury compared with that of the sham group, indicating increased leukocyte infiltration in the mouse liver (Fig. 3, P<0.01). However, treatment with NaHS (2 mg/kg

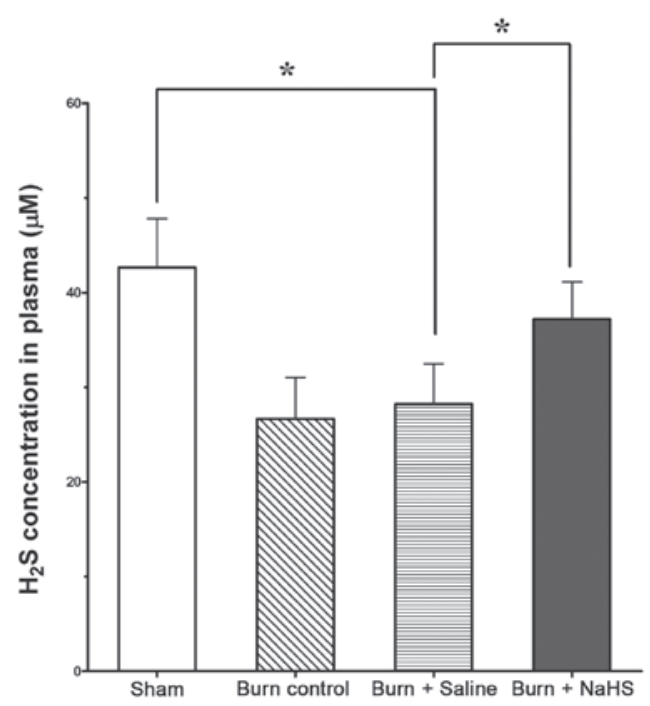

Figure 1. Effect of burn injury and NaHS treatment on plasma $\mathrm{H}_{2} \mathrm{~S}$ levels. The plasma $\mathrm{H}_{2} \mathrm{~S}$ levels of four groups were quantified and the results are expressed as the mean \pm SEM; $n=7$ for each group. Sham, mice which received no burn injuries; burn control, mice subjected to burn injury without treatment; burn + saline, treatment with the vehicle $(0.9 \% \mathrm{NaCl} ; 100 \mathrm{ml} / \mathrm{kg}$ body weight; subcutaneously, s.c.) following burn injury; and burn + NaHS, treatment with $\mathrm{NaHS}(2 \mathrm{mg} / \mathrm{kg}$ body weight, s.c.) following burn injury. " $\mathrm{P}<0.05$. NaHS, sodium hydrosulfide; $\mathrm{H}_{2} \mathrm{~S}$, hydrogen sulfide; $\mathrm{NaCl}$, sodium chloride.

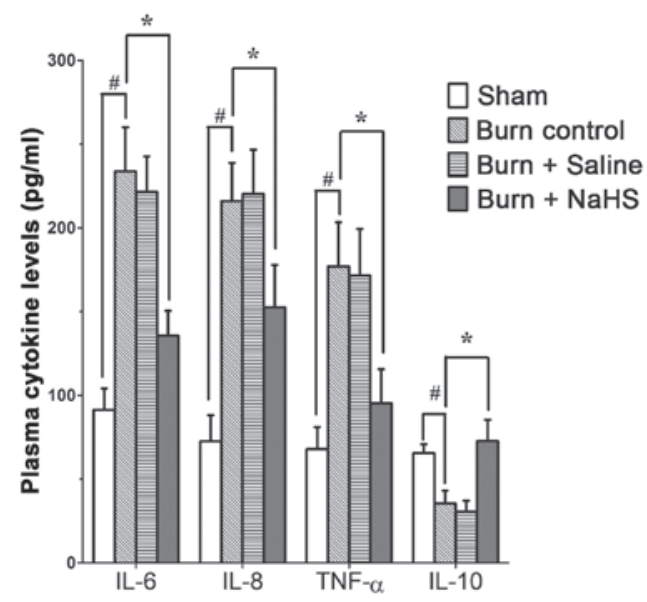

Figure 2. Effect of burn injury and NaHS treatment on plasma cytokine levels. Following burn injuries, mice were administered with the $\mathrm{H}_{2} \mathrm{~S}$ donor, $\mathrm{NaHS}$ or the vehicle (saline). After $10 \mathrm{~h}$, the plasma cytokine levels of four groups were measured by enzyme-linked immunosorbent assay and results are presented as the mean \pm SEM; $n=7$ for each group. Sham, plasma $\mathrm{H}_{2} \mathrm{~S}$ level in mice that received no burn injuries; burn control, mice subjected to burn injury without treatments; burn + saline, treatment with the vehicle $(0.9 \% \mathrm{NaCl} ; 100 \mathrm{ml} / \mathrm{kg}$ body weight; subcutaneously, s.c.) following burn injury; and burn + NaHS, treatment with NaHS ( $2 \mathrm{mg} / \mathrm{kg}$ body weight, s.c.) following burn injury. ${ }^{*} \mathrm{P}<0.01$ and ${ }^{*} \mathrm{P}<0.05$. NaHS, sodium hydrosulfide; $\mathrm{H}_{2} \mathrm{~S}$, hydrogen sulfide; $\mathrm{NaCl}$, sodium chloride.

of body weight, s.c.) significantly reduced the MPO activity (Fig. 3, P<0.05).

\section{Discussion}

Burn injuries remain one of the most widespread and devastating forms of trauma and are ranked among the 


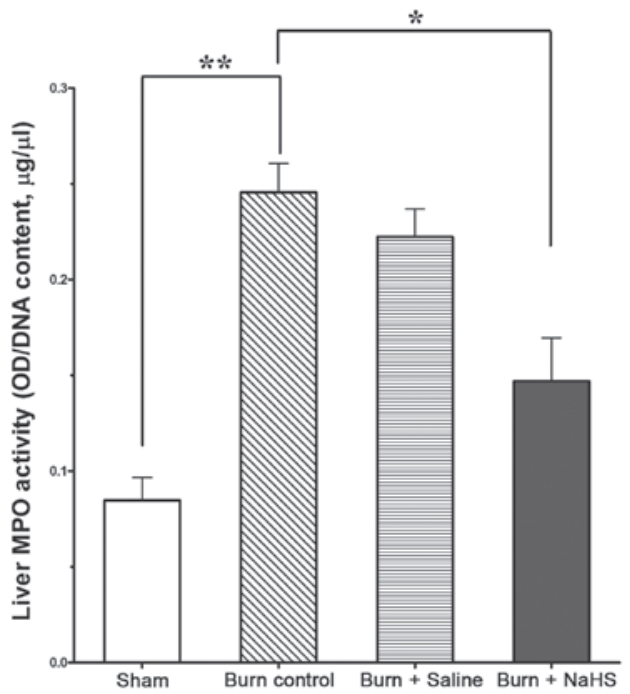

Figure 3. MPO activities in the livers of mice in the sham group (mice that received no burn injuries), burn control group (mice subjected to burn injury without treatment), saline group [mice subjected to burn injury and treated with the vehicle $(0.9 \% \mathrm{NaCl}, 100 \mathrm{ml} / \mathrm{kg}$ body weight; subcutaneously, s.c.)] and NaHS group (mice with burn injury treated with NaHS, $2 \mathrm{mg} / \mathrm{kg}$ body weight, s.c.). Data are presented as the mean \pm SEM; $n=7$ for each group ${ }^{*} \mathrm{P}<0.05$ and ${ }^{* *} \mathrm{P}<0.01$. MPO, myeloperoxidase; $\mathrm{NaCl}$, sodium chloride NaHS, sodium hydrosulfide.

leading causes of injury-related morbidity and mortality worldwide $(20,21)$. Although inflammation is important in the pathogenesis of burn injuries, severe burns often lead to systemic inflammatory response syndrome (SIRS), which may be responsible for the majority of the associated morbidity and mortality $(22,23) . \mathrm{H}_{2} \mathrm{~S}$ may be important in the regulation of the inflammatory process, however, the effects of $\mathrm{H}_{2} \mathrm{~S}$ on inflammation are controversial $(10,24,25)$. In the present mouse model, a predominant anti-inflammatory effect of $\mathrm{H}_{2} \mathrm{~S}$ was observed. Burn injuries resulted in a significant reduction in the $\mathrm{H}_{2} \mathrm{~S}$ levels in the plasma and an exaggerated inflammatory response was also observed, which was identified by significantly increased levels of IL-6, IL- 8 and TNF- $\alpha$, and a decreased level of IL-10. The MPO activity in the liver tissue of injured mice was also markedly increased. However, administration of $\mathrm{NaHS}$, an $\mathrm{H}_{2} \mathrm{~S}$ donor, alleviated the immune response, as demonstrated by the upregulated levels of a plasma anti-inflammatory cytokine (IL-10) and the reduced generation of pro-inflammatory cytokines (IL-6, IL-8 and TNF- $\alpha$ ). In this model, $\mathrm{H}_{2} \mathrm{~S}$ also decreased the elevated MPO activity of the liver tissue induced by burn injury.

$\mathrm{H}_{2} \mathrm{~S}$ has been demonstrated to be an essential mediator of severe burn injury-induced inflammation in mice (9). The results of the present study in mice showed that a $40 \%$ TBSA full thickness burn induced a significant decrease in plasma $\mathrm{H}_{2} \mathrm{~S}$ levels. Inflammatory cytokines exert well-characterized effects on the pathogenesis of severe burn-induced injury (26). IL-6 is produced by numerous cell types, including monocytes/macrophages, endothelial cells, fibroblasts and smooth muscle cells, in response to stimulation by endotoxin, IL-1 $\beta$ and TNF- $\alpha(27,28)$. Circulating levels of IL-6 are strong predictors of the severity of SIRS. The importance of IL-6 in the acute-phase response has been demonstrated by its ability to stimulate the synthesis of acute-phase proteins, including
C reactive protein, from hepatocytes in vitro and in vivo (29). Patients with systemic inflammatory conditions, such as sepsis or SIRS, also exhibit increased circulating levels of IL-8 (30). In acute pancreatitis, increased IL-8 levels predicted the severity of the disease (31). The anti-inflammatory cytokine IL-10 is a central immunosuppressive cytokine that regulates the innate and adaptive immune responses, resulting in inhibition of the alveolar macrophage production of pro-inflammatory mediators involved in SIRS (32). Increased IL-10 plasma levels in animal models of endotoxemia may inhibit the release of pro-inflammatory cytokines, including IL-1 $\beta$, IL- 6 and TNF- $\alpha$, from monocytes and macrophages, thereby preventing subsequent tissue damage (33). In the present study, it was determined that the levels of TNF- $\alpha$, IL-6 and IL- 8 in the plasma were significantly increased, while IL-10 secretion was inhibited by burn injury. Administration of NaHS significantly decreased the TNF- $\alpha$, IL-6 and IL-8 levels in the plasma, but elevated the IL-10 plasma levels. Inflammatory cytokines are essential in systemic immune dysfunction. The results demonstrated that NaHS decreased the levels of inflammatory cytokines and increased those of the anti-inflammatory cytokines, which suggested that $\mathrm{H}_{2} \mathrm{~S}$ may provide protection by alleviating the exaggerated inflammatory damage associated with burn injury. However, further studies are required to determine the precise mechanisms by which $\mathrm{H}_{2} \mathrm{~S}$ regulates the inflammatory response.

As leukocyte recruitment is pivotal in the pathogenesis of organ injury caused by burn injury (19), it was investigated whether NaHS is able to protect against organ injury by reducing leukocyte recruitment. It was determined that burn injury significantly enhanced the MPO activity in the liver, indicating increased neutrophil infiltration in this organ. Moreover, NaHS treatment reduced the MPO activity in the livers of mice subjected to burn injury, indicating attenuated neutrophil infiltration. These results were in accordance with those of a study demonstrating that NaHS modulated leukocyte-mediated inflammation by decreasing leukocyte adhesion and leukocyte infiltration (34).

However, Zhang et al demonstrated that mice subjected to $30 \%$ TBSA burn injury (10) exhibited significantly elevated plasma and hepatic $\mathrm{H}_{2} \mathrm{~S}$ levels, with a concomitant increase in liver and lung expression of cystathionine- $\beta$-synthase and cystathionine- $\gamma$-lyase (CSE), $8 \mathrm{~h}$ after injury. Prophylactic and therapeutic administration of PAG reduced burn-associated neutrophil accumulation and histological changes in the liver and lung tissues. Injection of $\mathrm{NaSH}(10 \mathrm{mg} / \mathrm{kg}$; i.p.) at the same time as burn injury aggravated the burn-associated tissue damage and inflammation. These results are not concordant with those observed in the present study, and thus may be due to the different animal models and doses of $\mathrm{H}_{2} \mathrm{~S}$ donors used. Severe full-thickness burn injury initially produces a large systemic inflammatory reaction characterized by leukocyte activation and plasma leakage in the microvasculature of tissues and organs remote from the wound. The degree of the inflammatory response correlates directly with the percentage of TBSA burnt (35). In our study, mice received a $40 \%$ TBSA burn injury, which was different from the previous animal model. Moreover, the dose and administration routes were different. In this study, the injected dose of NaHS was $2 \mathrm{mg} / \mathrm{kg}$ (s.c.), which was markedly lower than that in the study 
by Zhang et al (10 mg/kg; i.p.). It has been demonstrated that a high dose of $\mathrm{H}_{2} \mathrm{~S}$ donor may aggravate inflammation and injury while a low dose of $\mathrm{H}_{2} \mathrm{~S}$ decreases inflammation.

In conclusion, the present study demonstrated that in a murine model of inflammation induced by burn injury, administration of NaHS alleviated the immune response, as determined by the reversed MPO activity of the liver tissue, increased levels of an anti-inflammatory cytokine (IL-10) and reduced levels of pro-inflammatory cytokines (IL-6, IL-8 and TNF- $\alpha$ ). This study provides novel insights into the involvement of $\mathrm{H}_{2} \mathrm{~S}$ in attenuating the burn-induced systemic immune response. Modulation of endogenous $\mathrm{H}_{2} \mathrm{~S}$ or exogenous administration of $\mathrm{H}_{2} \mathrm{~S}$ may be a novel therapeutic strategy for immune dysfunction induced by burn injury.

\section{References}

1. Shakespeare P: Burn wound healing and skin substitutes. Burns 27: 517-522, 2001.

2. Evers LH, Bhavsar D and Mailänder P: The biology of burn injury. Exp Dermatol 19: 777-783, 2010.

3. Miller CL and Baker CC: Changes in lymphocyte activity after thermal injury. The role of suppressor cells. J Clin Invest 63 : 202-210, 1979.

4. Hansbrough JF, Zapata-Sirvent R, Peterson V, et al: Characterization of the immunosuppressive effect of burned tissue in an animal model. J Surg Res 37: 383-393, 1984.

5. Pae HO, Lee YC, Jo EK and Chung HT: Subtle interplay of endogenous bioactive gases ( $\mathrm{NO}, \mathrm{CO}$ and $\mathrm{H}(2) \mathrm{S})$ in inflammation. Arch Pharm Res 32: 1155-1162, 2009.

6. Wallace JL: Physiological and pathophysiological roles of hydrogen sulfide in the gastrointestinal tract. Antioxid Redox Signal 12: 1125-1133, 2010.

7. Bian JS, Yong QC, Pan TT, et al: Role of hydrogen sulfide in the cardioprotection caused by ischemic preconditioning in the rat heart and cardiac myocytes. J Pharmacol Exp Ther 316: 670-678, 2006.

8. Fiorucci S, Antonelli E, Mencarelli A, et al: The third gas: H2S regulates perfusion pressure in both the isolated and perfused normal rat liver and in cirrhosis. Hepatology 42: 539-548, 2005.

9. Whiteman M and Winyard PG: Hydrogen sulfide and inflammation: the good, the bad, the ugly and the promising. Expert Rev Clin Pharmacol 4: 13-32, 2011.

10. Zhang J, Sio SW, Moochhala S and Bhatia M: Role of hydrogen sulfide in severe burn injury-induced inflammation in mice. Mol Med 16: 417-424, 2010

11. Bhatia M, Wong FL, Fu D, Lau HY, Moochhala SM and Moore PK: Role of hydrogen sulfide in acute pancreatitis and associated lung injury. FASEB J 19: 623-625, 2005.

12. Collin M, Anuar FB, Murch O, Bhatia M, Moore PK and Thiemermann C: Inhibition of endogenous hydrogen sulfide formation reduces the organ injury caused by endotoxemia. $\mathrm{Br} \mathrm{J}$ Pharmacol 146: 498-505, 2005.

13. Zanardo RC, Brancaleone V, Distrutti E, Fiorucci S, Cirino G and Wallace JL: Hydrogen sulfide is an endogenous modulator of leukocyte-mediated inflammation. FASEB J 20: 2118-2120, 2006.

14. Elrod JW, Calvert JW, Morrison J, et al: Hydrogen sulfide attenuates myocardial ischemia-reperfusion injury by preservation of mitochondrial function. Proc Natl Acad Sci USA 104: 15560-15565, 2007.
15. Sidhapuriwala J, Li L, Sparatore A, Bhatia M and Moore PK: Effect of S-diclofenac, a novel hydrogen sulfide releasing derivative, on carrageenan-induced hindpaw oedema formation in the rat. Eur J Pharmacol 569: 149-154, 2007.

16. Hu LF, Wong PT, Moore PK and Bian JS: Hydrogen sulfide attenuates lipopolysaccharide-induced inflammation by inhibition of p38 mitogen-activated protein kinase in microglia. J Neurochem 100: 1121-1128, 2007.

17. Stevenson JM, Gamelli RL and Shankar R: A mouse model of burn wounding and sepsis. Methods Mol Med 78: 95-105, 2003.

18. Geng B, Cui Y, Zhao J, et al: Hydrogen sulfide downregulates the aortic L-arginine/nitric oxide pathway in rats. Am J Physiol Regul Integr Comp Physiol 293: R1608-R1618, 2007.

19. Bhatia M, Saluja AK, Hofbauer B, et al: Role of substance P and the neurokinin 1 receptor in acute pancreatitis and pancreatitis-associated lung injury. Proc Natl Acad Sci USA 95: 4760-4765, 1998.

20. Church D, Elsayed S, Reid O, Winston B and Lindsay R: Burn wound infections. Clin Microbiol Rev 19: 403-434, 2006.

21. Endorf FW and Ahrenholz D: Burn management. Curr Opin Crit Care 17: 601-605, 2011.

22. Dahiya P: Burns as a model of SIRS. Front Biosci 14: 4962-4967, 2009.

23. Greenhalgh DG, Saffle JR, Holmes JH IV, et al: American Burn Association consensus conference to define sepsis and infection in burns. J Burn Care Res 28: 776-790, 2007.

24. Oh GS, Pae HO, Lee BS, et al: Hydrogen sulfide inhibits nitric oxide production and nuclear factor-kappaB via heme oxygenase-1 expression in RAW264.7 macrophages stimulated with lipopolysaccharide. Free Radic Biol Med 41: 106-119, 2006.

25. Kubo S, Doe I, Kurokawa Y, Nishikawa H and Kawabata A: Direct inhibition of endothelial nitric oxide synthase by hydrogen sulfide: contribution to dual modulation of vascular tension. Toxicology 232: 138-146, 2007.

26. Cone JB, Wallace BH, Lubansky HJ and Caldwell FT: Manipulation of the inflammatory response to burn injury. J Trauma 43: 41-46, 1997.

27. Cohen J: The immunopathogenesis of sepsis. Nature 420: 885-891, 2002.

28. Bhatia M: Novel therapeutic targets for acute pancreatitis and associated multiple organ dysfunction syndrome. Curr Drug Targets Inflamm Allergy 1: 343-351, 2002.

29. Nijsten MW, Hack CE, Helle M, ten Duis HJ, Klasen HJ and Aarden LA: Interleukin- 6 and its relation to the humoral immune response and clinical parameters in burned patients. Surgery 109: 761-767, 1991.

30. Hack CE, Hart M, van Schijndel RJ, et al: Interleukin-8 in sepsis: relation to shock and inflammatory mediators. Infect Immun 60: 2835-2842, 1992

31. Makhija R and Kingsnorth AN: Levels of the chemokines growth-related oncogene alpha and epithelial neutrophil-activating protein 78 are raised in patients with severe acute pancreatitis. Br J Surg 89: 566-572, 2002.

32. Torre D, Tambini R, Aristodemo S, et al: Anti-inflammatory response of IL-4, IL-10 and TGF-beta in patients with systemic inflammatory response syndrome. Mediators Inflamm 9: 193-195, 2000.

33. Tamayo E, Alvarez FJ, Alonso O, et al: Effects of simvastatin on systemic inflammatory responses after cardiopulmonary bypass. J Cardiovasc Surg (Torino) 50: 687-694, 2009.

34. Volpato GP, Searles R, Yu B, et al: Inhaled hydrogen sulfide: a rapidly reversible inhibitor of cardiac and metabolic function in the mouse. Anesthesiology 108: 659-668, 2008.

35. Barber RC, Maass DL, White DJ and Horton JW: Increasing percent burn is correlated with increasing inflammation in an adult rodent model. Shock 30: 388-393, 2008. 